Pacific Journal of Mathematics

NOTE ON THE INEQUALITY OF THE ARITHMETIC AND 


\section{NOTE ON THE INEQUALITY OF THE ARITHMETIC AND GEOMETRIC MEANS}

\section{HaO Zhi ChUAN}

We show how to insert a continuum of additional terms (defined by an integral and depending on an arbitrary positive parameter) between the two sides of the generalized arithmetic-geometric mean inequality with weights. Applications give an inequality involving positive definite matrices and also a refinement of the inequality connecting the inscribed and circumscribed radii of a triangle.

We suppose throughout that

(1) $n \in \mathbb{N}$ and $a_{j}>0, \quad q_{j}>0(j=1, \ldots, n), \quad q_{1}+\cdots+q_{n}=1$.

Then we have the well-known inequality of the means (e.g. [2, \#9])

$$
\prod_{j=1}^{n} a_{j}^{q_{j}} \leq \sum_{j=1}^{n} q_{j} a_{j}
$$

with equality if and only if $a_{j}=a_{1}(j=1, \ldots, n)$.

THEOREM 1. If (1) holds and if $p>0$, then

$$
\prod_{j=1}^{n} a_{j}^{q_{j}} \leq\left\{p \int_{0}^{\infty}\left[\prod_{j=1}^{n}\left(x+a_{j}\right)^{q_{j}}\right]^{-p-1} d x\right\}^{-1 / p} \leq \sum_{j=1}^{n} q_{j} a_{j} .
$$

Proof. For $x \geq 0$, we replace $a_{j}$ by $x+a_{j}$ in (2); then

$$
0<\prod_{j=1}^{n}\left(x+a_{j}\right)^{q_{\jmath}} \leq \sum_{j=1}^{n} q_{j}\left(x+a_{j}\right)=x+\sum_{j=1}^{n} q_{j} a_{j} .
$$

Hence (for $p>0$ )

$$
\begin{aligned}
\int_{0}^{\infty}\left[\prod_{j=1}^{n}\left(x+a_{j}\right)^{q_{j}}\right]^{-p-1} d x \\
\quad \geq \int_{0}^{\infty}\left[x+\sum_{j=1}^{n} q_{j} a_{j}\right]^{-p-1} d x=\frac{1}{p}\left(\sum_{j=1}^{n} q_{j} a_{j}\right)^{-p} .
\end{aligned}
$$


In addition, by Hölder's integral inequality for $n$ functions [2, \#188 ],

$$
\begin{gathered}
\int_{0}^{\infty}\left[\prod_{j=1}^{n}\left(x+a_{j}\right)^{q_{j}}\right]^{-p-1} d x=\int_{0}^{\infty} \prod_{j=1}^{n}\left[\left(x+a_{j}\right)^{-p-1}\right]^{q_{j}} d x \\
\leq \prod_{j=1}^{n}\left[\int_{0}^{\infty}\left(x+a_{j}\right)^{-p-1} d x\right]^{q_{1}} \\
\quad=\prod_{j=1}^{n}\left[\int_{0}^{\infty}\left(x+a_{j}\right)^{-p-1} d x\right]^{q_{j}}=\prod_{j=1}^{n} \frac{1}{p}\left(a_{j}\right)^{-p q_{j}} .
\end{gathered}
$$

Multiplying (4) and (5) through by $p$ and raising both sides to the power $-1 / p$, we obtain respectively the right and left sides of (3).

REMARKs. (a) As examination of the proof of Theorem 1 shows, there is strict inequality in each part of (3) unless $a_{j}=a_{1}(j=$ $1, \ldots, n)$.

(b) If $q_{1}=\cdots=q_{n}=1 / n$ in (3) then, for any $p>0$,

(6)

$$
\begin{aligned}
\left(a_{1} a_{2} \cdots a_{n}\right)^{1 / n} & \leq\left\{p \int_{0}^{\infty}\left[\left(x+a_{1}\right) \cdots\left(x+a_{n}\right)\right]^{-(p+1) / n} d x\right\}^{-1 / p} \\
& \leq \frac{1}{n}\left(a_{1}+\cdots+a_{n}\right)
\end{aligned}
$$

Suppose $a_{i j}>0(i=1, \ldots, m ; j=1, \ldots, n)$; then $([2, \# 11])$

$$
\sum_{i=1}^{m} \prod_{j=1}^{n} a_{i j}^{q_{j}} \leq \prod_{j=1}^{n}\left(\sum_{i=1}^{m} a_{i j}\right)^{q_{j}} .
$$

If we then use $a_{j}:=\sum_{i=1}^{m} a_{i j}$ in (3) and combine (6) with the left side of (3), we obtain the apparently more general result (reducing to (3) for $m=1$ ):

Corollary 1.1. Let $a_{i j}>0(i=1, \ldots, m ; j=1, \ldots, n), p>$ 0 . Then

$$
\begin{aligned}
\sum_{i=1}^{m} \prod_{j=1}^{n} a_{i j}^{q_{j}} & \leq\left\{p \int_{0}^{\infty}\left[\prod_{j=1}^{n}\left(x+\sum_{i=1}^{m} a_{i j}\right)^{q_{j}}\right]^{-p-1} d x\right\}^{-1 / p} \\
& \leq \sum_{i=1}^{m} \sum_{j=1}^{n} q_{j} a_{i j} .
\end{aligned}
$$


If $A$ is a real positive definite $n \times n$ matrix (namely the quadratic form $v A v$ is positive for all non-trivial $n$-vectors $v$ ) then it is well known that the eigenvalues $a_{j}(j=1, \ldots, n)$ are all positive. Indeed, since the $a_{j}$ are the solutions of the polynomial equation $|\lambda I-A|:=\operatorname{det}(\lambda I-A)=0$, we clearly also have

$$
|x I+A|=\prod_{j=1}^{n}\left(x+a_{j}\right) \quad \text { for any } x \in \mathbb{R} .
$$

From this equation $(x=0)$ and the definition of the trace, we therefore have

$$
|A|=\prod_{j=1}^{n} a_{j}>0, \quad \operatorname{tr} A=\sum_{j=1}^{n} a_{j} .
$$

Using these $a_{j}$ in (6), we then obtain

COROllary 1.2. Let $A$ be a real positive definite $n \times n$ matrix and $p>0$. Then

$$
|A|^{1 / n} \leq\left\{p \int_{0}^{\infty}|x I+A|^{-(p+1) / n} d x\right\}^{-1 / p} \leq \frac{1}{n} \operatorname{tr} A .
$$

There is an analogue of this result similar to Corollary 1.1 ; replace $A$ by $\sum_{i=1}^{m} A_{i}$ in Corollary 1.2 and use Minkowski's inequality for positive definite $n \times n$ matrices (e.g. [1, p. 70, Theorem 15]), that

$$
\sum_{i=1}^{m}\left|A_{i}\right|^{1 / n} \leq\left|\sum_{i=1}^{m} A_{i}\right|^{1 / n}
$$

(this is really (7) in disguise, with $\left.q_{1}=\cdots=q_{n}=1 / n\right)$. We obtain immediately

Corollary 1.3. Let $A_{i}(i=1, \ldots, m)$ be real positive definite $n \times n$ matrices, and $p>0$. Then

$$
\begin{aligned}
\sum_{i=1}^{m}\left|A_{i}\right|^{1 / n} & \leq\left\{p \int_{0}^{\infty}\left|x I+\sum_{i=1}^{m} A_{i}\right|^{-(p+1) / n} d x\right\}^{-1 / p} \\
& \leq \frac{1}{n} \operatorname{tr}\left(\sum_{i=1}^{m} A_{i}\right) .
\end{aligned}
$$

As a further application of Theorem 1, we show how to insert additional terms between the two sides of Euler's inequality $2 r \leq R$ (e.g. 
see $[3$, p. 79$]$ or $[4$, v. $2: \S 17.3$, p. 161]) connecting the circumscribed radius $R$ and the inscribed radius $r$ of a triangle. If the triangle has angles $A, B, C$ with sides $a, b, c$ opposite these angles, and area $\Delta$, then, using the sine rule,

$$
R=\frac{a+b+c}{2(\sin A+\sin B+\sin C)} \geq \frac{a+b+c}{3 \sqrt{3}} .
$$

Also

$$
2 r(a+b+c)=4 \Delta \leq \sqrt{3}(a b c)^{2 / 3}
$$

(see [4, v.2: $\S 17.3$, pp. 161, 372]) and so, by the arithmetic-geometric mean inequality,

$$
2 r \leq \frac{\sqrt{3}(a b c)^{2 / 3}}{a+b+c} \leq \frac{\sqrt{3}(a b c)^{2 / 3}}{3(a b c)^{1 / 3}}=\frac{(a b c)^{1 / 3}}{\sqrt{3}} .
$$

Now, by (11), (12) and (6), we have:

COROLlARY 1.4. If $a, b, c$ are the sides of a triangle, with inscribed radius $r$ and circumscribed radius $R$, then, for any $p>0$,

$$
2 r \sqrt{3} \leq(a b c)^{1 / 3} \leq J(a, b, c ; p) \leq \frac{1}{3}(a+b+c) \leq R \sqrt{3},
$$

where

$$
J(a, b, c ; p):=\left\{p \int_{0}^{\infty}[(x+a)(x+b)(x+c)]^{-(p+1) / 3} d x\right\}^{-1 / p} .
$$

There is strict inequality throughout (13) unless $a=b=c$.

I wish to thank D. Russell for assistance in English language presentation and for improvements of some details in the results.

\section{REFERENCES}

[1] E. F. Beckenbach and R. Bellman, Inequalities, Springer-Verlag, Berlin-Heidelberg-New York: 4th printing, 1983.

[2] G. H. Hardy, J. E. Littlewood and G. Pólya, Inequalities, University Press, Cambridge (2nd edn. reprinted), 1988.

[3] N. D. Kazarinoff, Geometric Inequalities, Random House, New York, 1961.

[4] G. Pólya and G. Szegö, Problems and Theorems in Analysis, vols. 1,2. SpringerVerlag, Berlin-Heidelberg-New York: English translation, 1976.

Received July $15,1988$.

ECONOMIC INFORMATION DEPARTMENT

Gui-Zhou Finance \& ECONOMic Institute

People's RePublic of China 


\section{PACIFIC JOURNAL OF MATHEMATICS EDITORS}

\author{
V. S. VARADARAJAN \\ (Managing Editor) \\ University of California \\ Los Angeles, CA 90024-1555-05 \\ Herbert Clemens \\ University of Utah \\ Salt Lake City, UT 84112 \\ Thomas ENRIGHT \\ University of California, San Diego \\ La Jolla, CA 92093
}

R. FINN

Stanford University

Stanford, CA 94305

Hermann FlaschKa

University of Arizona

Tucson, AZ 85721

VAughan F. R. Jones

University of California

Berkeley, CA 94720

Steven Kerckhoff

Stanford University

Stanford, CA 94305
RobION KIRBY

University of California

Berkeley, CA 94720

C. C. MOore

University of California

Berkeley, CA 94720

HAROLd STARK

University of California, San Diego La Jolla, CA 92093

\begin{tabular}{|c|c|c|c|c|}
\hline & ASSOCIA & E EDI & & \\
\hline R. ARENS & $\begin{array}{l}\text { E. F. BECKENBACH } \\
(1906-1982)\end{array}$ & NeumanN & $\begin{array}{c}\text { F. WoLF } \\
(1904-1989)\end{array}$ & K. Yoshida \\
\hline & SUPPORTINC & INSTI & TIONS & \\
\hline UNIVERSITY & ARIZONA & UNIVERS & OF OREGON & \\
\hline UNIVERSITY & BRITISH COLUMBIA & UNIVER & OF SOUTHEI & CALIFORNIA \\
\hline CALIFORNIA & STITUTE OF TECHNOLOGY & STANFOI & UNIVERSITY & \\
\hline UNIVERSITY & CALIFORNIA & UNIVER & OF HAWAII & \\
\hline MONTANA S & TE UNIVERSITY & UNIVER & OF TOKYO & \\
\hline UNIVERSITY & NEVADA, RENO & UNIVER & OF UTAH & \\
\hline NEW MEXIC & TATE UNIVERSITY & WA & N STATE UN & ERSITY \\
\hline OREGON ST & UNIVERSITY & & OF WASHINC & $\mathrm{ON}$ \\
\hline
\end{tabular}




\section{Pacific Journal of Mathematics}

\section{Vol. 143, No. $1 \quad$ March, 1990}

Walter Bergweiler, On the fix-points of composite functions $\ldots \ldots \ldots \ldots \ldots 1$ Aldo Biancofiore, Maria Lucia Fania and Antonio Lanteri, Polarized surfaces with hyperelliptic sections $\ldots \ldots \ldots \ldots \ldots \ldots \ldots \ldots \ldots$

Ciprian Borcea, Deforming varieties of $k$-planes of projective complete

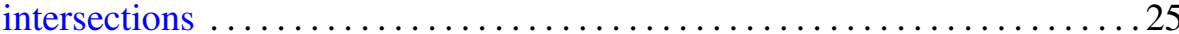

Morton Brown, Fixed points for orientation preserving homeomorphisms of

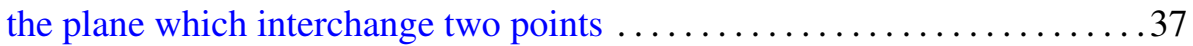

Hao Zhi Chuan, Note on the inequality of the arithmetic and geometric means

Paul Henry Edelman and Dennis E. White, Codes, transforms and the

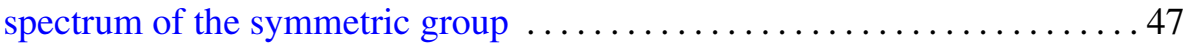

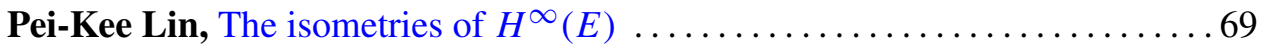

James J. Moloney, Residue class domains of the ring of convergent

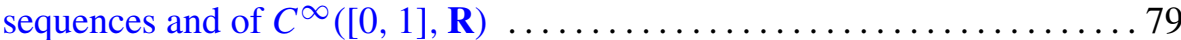

Zhong-Jin Ruan, The structure of pure completely bounded and completely

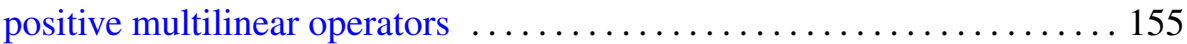

Wolfgang Ruess and William H. Summers, Weakly almost periodic semigroups of operators

Gideon Schwarz, A pretender to the title "canonical Moebius strip" . . . . . . 195

Ryszard Szwarc, Banach algebras associated with spherical representations of the free group 